\title{
Analisis Faktor Kendala dalam Pengajuan Sertifikat Halal. (Studi Kasus: Pelaku Usaha Mikro, Kecil dan Menengah Makanan Beku diJabodetabek)
}

\author{
Constraints Factor Analysis in Halal CertificateSubmission \\ (Case Study: Small Medium Enterprises of Frozen Food in Jabodetabek) \\ T. Maryati ${ }^{1)}$, R. Syarief ${ }^{2}$, R. Hasbullah ${ }^{3)}$ \\ ${ }^{1)}$ Manajemen Bisnis, Sekolah Pascasarjana, Institut Pertanian Bogor \\ 2) Departemen Ilmu dan Teknologi Pangan, Fakultas Teknologi Pertanian, IPB \\ 3) Departemen Teknik Mesin dan Biosistem, Fakultas Teknologi Pertanian, IPB \\ Correspondence author: Jalan Kemanggisan Utama Raya No 19B-3 Slipi Jakarta Barat, tati.gumkemindo@ \\ gmail.com, 087873122533
}

\begin{abstract}
Indonesia with high Muslim community is potential market for halal products. High percentage of Small Medium Enterprises make it as driver of commerce in Indonesia, but the fact those enterprises cannot submit halal certificate makes this research conducted to identify enterprises characteristic, analyze the constraints and formulate strategies in halal certificate submission. Information extracted from 30 frozen food enterprises in Jakarta, Bogor, Depok, Tangerang dan Bekasi and 10 experts in the field related with convenience and purposive sampling are enterprises educational background, business period, earnings, and industrial facilities including the machines used, how many are unlicensed industrial, marketing authorization, and halal certificate. The determination of alternative uses analytical hierarchy process with the help of Expert Choice 2003. Results showed that enterprises are micros that do not have proper production facility and using simple technology. Marketing authorizationis obstacle in halal certificates submission. Improving the competitiveness $(0.575)$ with assistance $(0.321)$ from Badan Pengawas Obat dan Makanan (0.484) is the main priority. Factors the most influenceare production facility $(0.572)$, raw material $(0.233)$, attitude of enterprises $(0.838)$ and legality $(0.432)$. The best alternative strategies recommended are fostering Good Production (0.343), Bureaucratic of marketing authorization accelerated and simplified $(0.169)$ and intense coaching $(0.153)$.
\end{abstract}

Keywords: Small Medium Enterprises, marketing authorization, frozen food, halal certificate”.

\section{PENDAHULUAN}

Penduduk Indonesia yang mayoritas Muslim merupakan pasar potensial untuk aneka produk halal. Prosentase jumlah pelaku usaha mikro kecil dan menengah yang tinggi (usaha mikro: $98.79 \%$, usaha kecil: $1.11 \%$, dan usaha menengah: $0.09 \%$ ), dan usaha besar hanya $0.01 \%$ (Kementrian Koperasi dan Usaha Kecil Menengah 2013) dari total unit usaha di Indonesia, menjadikan pelaku usaha mikro kecil dan menengah (UMKM) berperan sebagai penggerak perniagaan di Indonesia.

Zulkarnain (2014) mengemukakan bahwa sepanjang tahun, peminat produk halal meningkat pesat di kalangan masyarakat Muslim bahkan bukan Muslim. Peningkatkan tersebut disebabkan adanya peningkatan kesadaran konsumen untuk mengonsumsi produk halaldan bagi Muslim hal ini merupakan keharusan menurut agama. Kualitas merupakan jaminan standardalam makanan dan minuman sedangkan untuk pelanggan Muslim standar memecahkan keraguan mereka dalam pembelian makanan (Samori et al. 2014). Bagi konsumen bukan Muslim di seluruh dunia mengonsumsi produk halal karena produk halal berkualitas tinggi, aman dan higienis. Alasan lain suatu Negara menyediakan makanan halal seperti yang terjadi di Kanada,karena meningkatnya imigran Muslim (Alhabshi 2013). Kordnaeij et al. (2013) mengatakan iklan, kualitas, norma dan agama dianggap sebagai faktor pembuat keputusan terhadap produk halal.

Produk halal merupakan kebutuhan Muslim dan ketersediaanya merupakan suatu keharusan di negara yang mengakui keberadaan Muslim. Quantaniah et al.(2013) mengemukakan bahwa agama memainkan salah satu peran yang paling berpengaruh menentukan pilihan makanan. Sementara Ahmad et al. (2011) mengatakan bisnis halal untuk Muslim merupakan bisnis yang berkomitmen dengan agama. Permasalahan produk halal, selain menyangkut bisnis juga menyangkut sains, inovasi dan teknologi serta agama, yang melibatkan beberapa pihak terkait seperti pelaku usaha, saintis dan ahli teknologi serta ahli agama atau ulama. Hal inilah yang membuka pemikiran bahwa teknologi tinggi dan kompetensi para saintis dalam melakukan pengujian dan penelitian halal ada 
didalam Islam.Ketersediaan dan kemudahan memperoleh produk halal merupakan pemenuhan hak Muslim.

Fakta dilapangan bahwa pelaku UMKM makanan beku banyak yang tidak bisa mengajukansertifikat halal dapat mengakibatkan bisnis produk makanan beku halal di Indonesia sulit berkembang dan berpotensi menimbulkan konflik.

Berdasarkan latar belakang tersebut tujuan penelitian ini adalah untuk mengidentifikasi karakteristik UMKM makanan beku di Jabodetabek, menganalisis faktor kendala dalam pengajuan sertifikat halal produk makanan beku dan merumuskan strategi untuk mengatasi permasalahan pelaku UMKM makanan beku dalam mengajukan sertifikat halal.

\section{MATERI DAN METODE}

Penelitian dilakukan pada pelakuusaha mikro kecil dan menengah makanan beku di Jabodetabek denganperiode penelitian dari bulan Januari - April 2016. Kegiatan penelitian meliputi survei pendahuluan, pengumpulan data kuesioner dari 30 UMKM makanan beku di Jabodetabek yang mayoritas berbahan baku daging dan olahannya dan sebagian kecil produk olahan susu dan kue. Pengambilan sampel menggunakan gabungan judge mental sampling/ purposive sampling dan convenience sampling. Pemilihan responden tidaklah mudah karena beberapa pelaku tidak berkenan menjadi responden dan beberapa pelaku yang bulan sebelumnya memproduksi makanan beku tapi karena sulit mendapat izin edar MD dan tidak bisa mengajukan sertifikat halal, akhirnya bulan berikutnya pelaku tersebut tidak memproduksi makanan beku lagi. Alasan itulah yang mendorong pemilihan responden berdasarkan kriteria yang dirumuskan oleh peneliti, sehingga dipengaruhi pengalaman dan subjektifitas dari peneliti (Sugiharto et al. 2001). Data yang diperoleh dari kuesioner ini adalah data yang menggambarkan karakteristik pelaku berdasarkan latar belakang pendidikan pelaku, masa usaha, omzet, fasilitas produksi yang dimiliki, mesin produksi yang dipergunakan, dan jumlah pelaku yang tidak memiliki izin industri, izin edar MD dan sertifikat halal, yang diolah secara deskriptif dan tabulasi silang.

Selanjutnya dilaksanakan diskusi secara terfokus (FGD) di kantor BPOM pusat yang dihadiri oleh 6 orang pakar dibidang standardisasi produk pangan Badan Pengawasan Obat dan Makanan (BPOM), pakar dibidang penilaian keamanan pangan, pakar dibidang surveilen produk pangan, pakar izin edar Merk Dalam negri (MD), pakar Izin Usaha Mikro kecil (IUMK) dari kecamatan, pakar Izin Usaha Industri (IUI) dari Badan Pelayanan Perizinan Terpadu dan Penanaman Modal (BPPTPM) yang sebelumnya Badan Pelayanan Terpadu Satu Pintu (BPTSP) Pusat. Untuk lebih melengkapi informasi, selanjutnya dilaksanakan wawancara mendalam dengan 4 pakar, dibidang perizinan dari BPPTPM daerah yaitu Kota Bogor, Depok, Tangerang dan Bekasi. Penetapan sumber informasi atau responden pakar terkait dengan pertimbangan: keberadaan responden, keterjangkauan dan kesediaan untuk diwawancarai, reputasi, kedudukan dan telah menunjukkan kredibilitas sebagai pakar, serta pengalaman pribadi bahwa seseorang tersebut mampu memberi saran yang benar (Eriyatno 2007).

Berdasarkan hasil FGD disepakati bahwa fokus yang ingin dicapaiadalah UMKM makanan beku mudah mendapat izin edar MD sehingga bisa mengajukan halal, dengan tujuan peningkatkan daya saing, kesejahteraan masyarakat meningkat, pembangunan disegala sektor meningkat dan perekonomian meningkat. Sementara aspek-aspek yang memengaruhi tercapainya tujuan adalah keamanan pangan, legalitas usaha, kemudahan akses pembiayaan, dan pendampingan dengan aktor yang berperan didalamnya adalah BPOM, UMKM, Kecamatan dan BPPTPM.Selanjutnya menetapkan faktorfaktor yang berpengaruh di setiap aktor yang hasilnya dijadikan alternatif strategi yang dianalisis menggunakan TeknikAnalytical Hierarchy Process (AHP).

Penentuan strategi alternatif pada penelitian ini berdasarkan pengujian preferensi pakar dengan menggunakan AHP.Prinsip kerja AHP adalah menyederhanakan persoalan kompleks menjadi bagianbagian yang tertata dalam suatu hirarki.Nilai numerik diberikan para ahli terhadap kepentingan setiap variabel kemudian dibandingkan secara relatif dengan variabel yang lain.Selanjutnya sintesa dilakukan untuk menetapkan variabel yang memiliki prioritas tertinggi dan memiliki peran dapat memengaruhi hasil pada sistem.Keunggulan AHP yang dapat menggambarkan secara grafis menjadi lebih mudah dipahami oleh semua pihak. Selain itu AHP juga menguji konsistensi penilaian, jika terjadi penyimpangan yang terlalu jauh dari nilai konsistensi sempurna, maka penilaian harus diperbaiki atau hirarki harus di struktur ulang (Marimin 2004).

Selanjutnya adalah menyebarkan kuesioner yang telah disusun berdasarkan struktur AHP kepada 10 pakar tersebut diatas.Semua hal tersebut dijadikan bahan untuk merumuskan strategi dalam membantu persoalan para pelaku UMKM makanan beku di Jabodetabek dalam pengurusan sertifikat halal dengan menggunakan AHP dengan bantuan perangkat lunak Expert Choice 2003.

\section{HASIL DAN PEMBAHASAN}

\section{Karakteristik UMKM Makanan Beku di Jabodetabek.}

Untuk mengidentifikasi karakteristik UMKM makanan beku di Jabodetabek dikaji melalui beberapa hal yaitu latar belakang pendidikan pelaku UMKM makanan beku di Jabodetabek, masa usaha, dan penghasilan penjualannya.Latar belakang pendidikan pelaku UMKM makanan beku yang mayoritas ditempati lulusan dari Strata S-1 (53.3\%)diharapkan lebih mudah untuk memahami dan mengimplementasikan pelatihan/ pembinaan yang diberikan.Hasil pengolahan data dengan tabulasi silang seperti tampak pada Tabel 1, diketahui bahwa yang memiliki latar belakang pendidikan lebih tinggi memiliki masa usaha lebih panjang.

Kriteria pelaku UMKM berdasarkan Undang Undang Nomor 20 Tahun 2008 Bab IV pasal 6 adalah: 
Tabel 1. Hubungan antara latar belakang pendidikan dengan masa usaha pelaku UMKM makanan beku di Jabodetabek

\begin{tabular}{lcccc}
\hline Pendidikan & \multicolumn{4}{c}{ Masa Usaha (tahun) } \\
\cline { 2 - 5 } & $<5$ & $5-<10$ & $10-<15$ & $>15$ \\
\hline SMP/SMA & 1 & 0 & 0 & 0 \\
D-3 & 3 & 0 & 0 & 0 \\
S-1 & 7 & 4 & 1 & 0 \\
S-2 & 1 & 0 & 0 & 1 \\
\hline
\end{tabular}

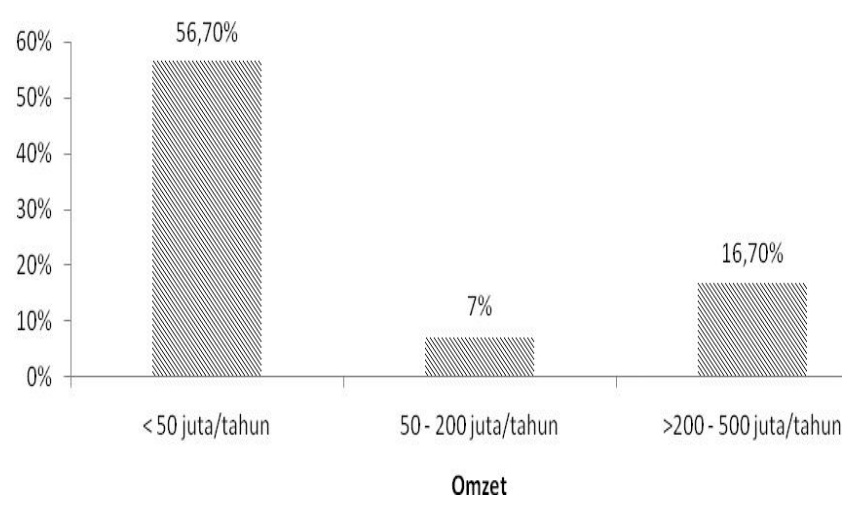

Gambar 1 Omzet UMKM makanan beku di Jabodetabek

usaha mikro memiliki hasil penjualan tahunan paling banyak Rp300000 000, usaha kecil paling banyak Rp2500 000 000dan usahamenengah paling banyak Rp50 000000 000. Berdasarkan Gambar 1, pelaku UMKM makanan beku di Jabodetabek yang memiliki omzet kurang dari 50 juta rupiah per tahun sebanyak 56.7\%, omzet 50-200 juta rupiah per tahun sebanyak $7 \%$, omzet $200-500$ juta rupiah per tahun $16.7 \%$.

\section{Kendala UMKM makanan beku mendapat sertifikat} halal

Proses pengajuan sertifikat halal berdasarkan ketentuan dari LPPOM-MUI saat ini, pelaku usaha harus memahami persyaratan sertifikasi halal dan mengikuti pelatihan sistem jaminan halal serta menerapkannya, melengkapi dokumen: daftar produk, daftar bahan dan dokumen bahan, matriks produk, manual sistem jaminan halal, diagram alir proses, daftar alamat fasilitas produksi, bukti sosialisasi kebijakan halal, bukti pelatihan internal dan bukti audit internal, melakukan pendaftaran sertifikasi halal, melakukan monitoring pre-audit dan pembayaran akad sertifikasi, pelaksanaan audit, melakukan monitoring pasca audit, memiliki izin edar PIRT/ MD, memiliki izin edar MD untuk produk yang beresiko tinggi. Seluruh persyaratan tersebut dapat disiapkan oleh pelaku usaha kecuali izin edar MD dari BPOM dan IUI/IUMK dari BPPTPM/Kecamatan.

Untuk mendapatkan izin edar MD berdasarkan ketentuan BPOM, pelaku usaha harusmemiliki Izin Usaha IUMK atau IUI dari Pemda setempat sesuai Pedoman Pelaksanaan IUMK (2015), melakukan pengujian produk ke laboratorium yang sudah diakreditasikan, mengajukan permohonan izin edar MD ke Badan POM RI (rangkap 2), mengisi formulir permohonan MD dan menyertakan lampirannya, menyertakan rancangan etiket/label produk, mengirimkan berkas permohonan ke Direktorat Penilaian Keamanan Pangan Badan POM RI.

Ketika mengajukan sertifikat halal, pelaku usaha melengkapi dokumen dengan izin edar MD, dan ketika mengurus izin edar MD pelaku usaha melengkapi dokumen dengan izin industri.

Pada Tabel 2 tampak bahwa pelaku UMKM makanan beku di Jabodetabek yang tidak memiliki izin edar MD sebanyak 96.7\%, yang tidak memiliki sertifikat halal $60 \%$ dan yang tidak memiliki IUI $60 \%$.

Pada Gambar 2, faktor utama yang menjadi kendala pelaku UMKM makanan beku tidak bisa mengajukan sertifikat halal adalah kelengkapan dokumen (33.3\%). Kelengkapan dokumen yang dimaksud adalah melampirkan seluruh persyaratan yang diminta dan diantaranya harus melampirkan izin edar MD dan izin industri IUI/IUMK dimana keduannya bisa diperoleh dari BPOM dan BPPTPM/Kecamatan.Izin industri meskipun sudah tidak berbayar namun masih dianggap rumit oleh para pelaku usaha sehingga diharapkan IUMK yang lebih sederhana dapat segera diimplementasikan di seluruh wilayah.Izin edar MD yang sangat ketat dalam pelaksanaannya sering kali membuat para pelaku usaha menyerah sebelum mengajukan. BPOM sebagai lembaga yang memiliki kewenangan sebagai pengawas makanan yang beredar di Indonesia bertanggung jawab terhadap keamanan pangan Indonesia. Audit dan pengecekan laboratorium terhadap material yang tidak dilengkapi dokumen perlu dilakukan karena saat ini banyak produk yang dihasilkan dari proses teknologi sehingga perlu diketahui ketertelusurannya. Di Pakistan menurut Salman (2011), penelitian yang dilakukan dapat menjadi titik awal

Tabel 2 Kepemilikan izin edar MD, izin usaha, dan sertifikat halal.

\begin{tabular}{lccc}
\hline UMKM & MD & Halal & IUI \\
\cline { 2 - 4 } & \multicolumn{3}{c}{$\%$} \\
\hline Tidak memiliki & 96,7 & 56,7 & 76,7 \\
Memiliki & 0 & 40 & 20 \\
Tidak Menjawab & 3,3 & 3,3 & 3,3 \\
\hline
\end{tabular}

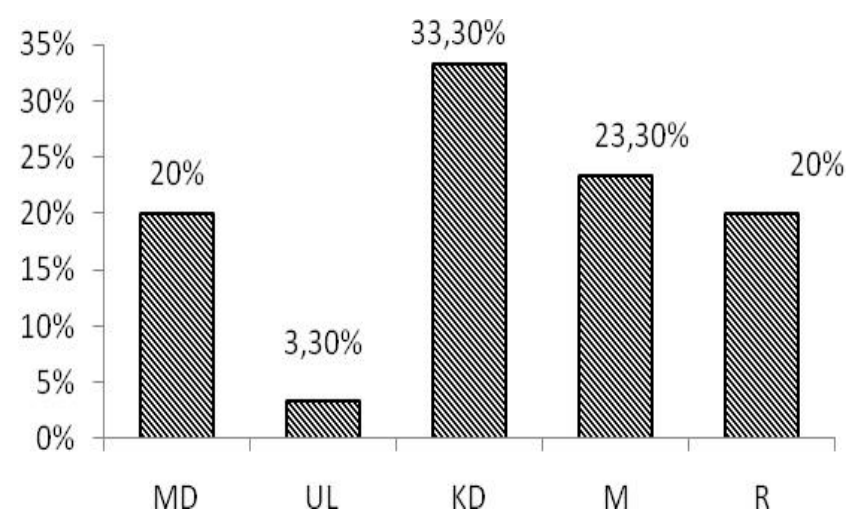

Gambar 2 Faktor kendala UMKM makanan beku mengurus sertifikat halal.

Keterangan:

$\mathrm{MD}=$ Izin edar MD; UL= Uji Lab; KD= Kelengkapan

Dokumen; $\mathrm{M}=$ Mahal; $\mathrm{R}=$ Rumit 


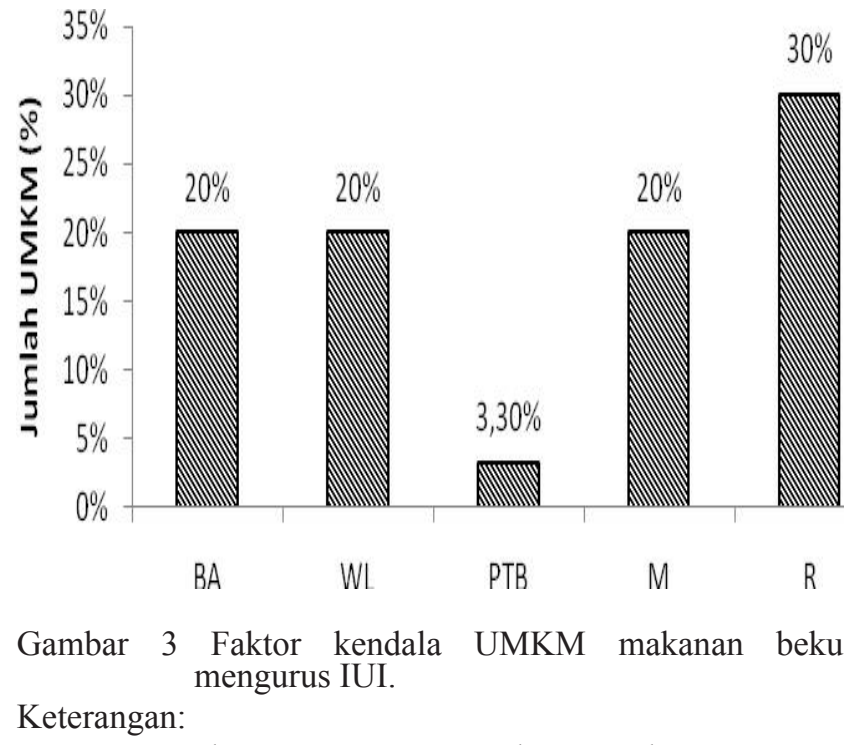

$\mathrm{BA}=$ Banyak aturan; $\mathrm{WL}=$ Waktunya lama; $\mathrm{PTB}=$ Pelayanan tidak baik; $M=$ Mahal; $\mathrm{R}=$ Rumit

untuk pengusaha dalammemahami kebutuhan sertifikasi makanan halal yang diakreditasi,karena banyak produk makanan lokal dan impor yang tersedia di Pakistan memiliki logo halal tetapi tidak memiliki ketertelusuran.

Pada Gambar 3 tampak faktor kendala mendapatkan Izin Usaha Industri (IUI) sebesar 30\% adalah rumit dalam pengurusan. Banyak dokumen yang harus dilampirkan oleh para UMKM ketika mengurus IUI. Peraturan Presiden Nomor 98 Tahun 2014 menjelaskan bahwa izin usaha untuk pelaku UMKM cukup dengan Izin Usaha Mikro Kecil (IUMK) dari Kecamatan.Berdasarkan hasil wawancara mendalam dengan para kepala perizinan Jabodetabek, IUMK memang belum diimplementasikan di seluruh wilayah karena masih dalam perbincangan dengan tingkat pusat.Dua alasan lain yang merupakan kendala dalam pengajuan izin industri IUI adalah waktu pengerjaan yang lama dan mahal, padahal saat ini waktu yang dibutuhkan relatif lebih singkat karena sudah on line dan sudah disediakan fasilitas tracking sehingga pelaku usaha dapat mengawasi sendiri jika ada pengerjaan dokumen yang terhambat.

Pada Gambar 4, diketahui bahwa kendala pelaku UMKM makanan beku mengurus MD adalah birokrasi pengurusan izin edar MD yang rumit (43.3\%). Berdasarkan Peraturan Kepala BPOM NomorHK.03.1.23.04.12.2205 Tahun 2012, produk makanan beku harus berizin edar MD, karena termasuk kedalam kelompok produk beresiko tinggi.Kategori produk yang terbuat dari bahan dasar hewani merupakan salah satu produk yang beresiko tinggi (Halal Directory LPPOM MUI 2013-2014).Produk makanan beku yang mayoritas bahan bakunya berupa daging dan hasil olahannya disimpan pada suhu dingin (dibekukan) supaya aktivitas mikrobiologi menjadi terhambat sehingga daya simpan produk menjadi lebih panjang (Evans 2008).Bahan baku daging yang digunakan harus diperoleh dari toko atau rumah potong hewan yang sudah bersertifikat halal seperti dijelaskan dalam pedoman pemenuhan kriteria sistem jaminan halal di rumah potong hewan (HAS 20103 LPPOM MUI 2012).

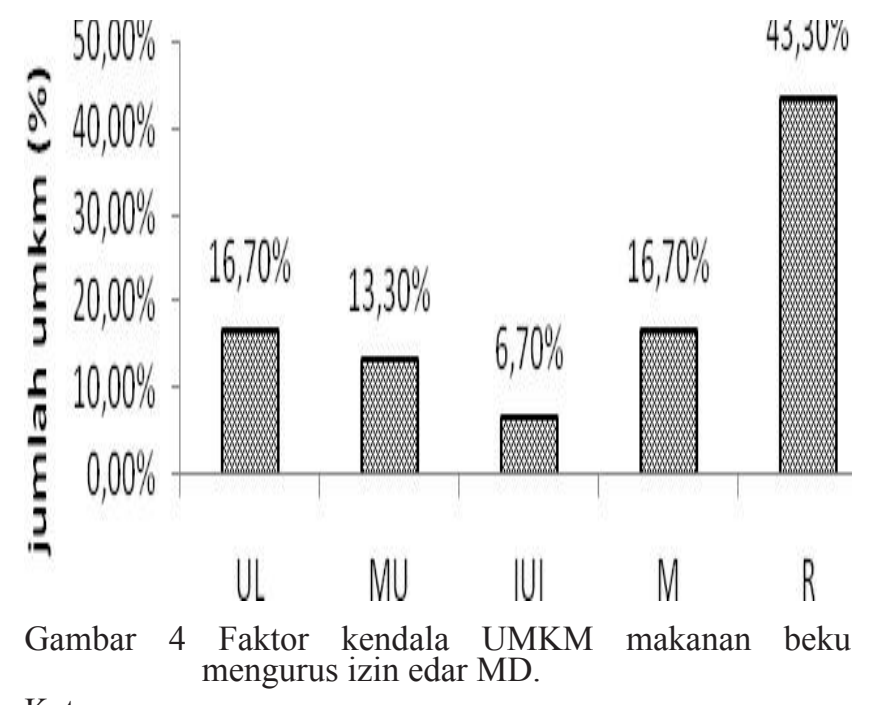

Keterangan:

$\mathrm{UL}=\mathrm{Uji}$ lab; MU=Modal usaha; IUI=Izin usaha industri; $\mathrm{M}=$ Mahal; $\mathrm{R}=$ Rumit.

Daging yang berasal dari hewan mati sebelum disembelih, pemingsanan yang menyebabkan cedera pada batang otak,penyembelihan yang menyebabkan leher/kepala/badan terpotong, penyembelihan dari arah belakang leher, dan penyembelihan yang tidak memutus tiga saluran merupakan bahan bakuyang gagal halal/ tidak halal. Sulitnya pengawasan dalam penggunaan bahan baku khususnya daging yang gagal halal dalam penyembelihannya membutuhkan suatu keahlian tersendiri dalam mengidentifikasi daging dari hewan yang penyembelihannya tidak sesuai syariat Islam atau istilahnya gagal halal tersebut.Faktor lain yang harus diperhatikan dan dikerjakan oleh pelaku UMKM adalah pengujian laboratorium. Pengujian dilakukan untuk bahan baku yang tidak memiliki dokumen pendukung menyulitkan dalam penelusurannya. Pengujian juga dilakukan terhadap produk yang dihasilkan.Salah satu cara untuk membuktikan sanitasinya baik dan sumber air yang digunakan layak dipakai untuk produksi adalah dengan pengujian mikrobiologi.

Standar kehalalan suatu produk harus jelas dan seragam serta diikuti semua pihak untuk menghindari perbedaan persepsi tentang halal. Untuk itulah pentingnya memiliki SNI (Standar Nasional Indonesia) tentang produk halal dan SNI sistem manajemen halal. Hal ini bukan saja menjadi perhatian bangsa Indonesia tapi standar harus menjadi perhatian bagi negara-negara Islam di dunia seperti dikemukakan oleh Halim et al. (2012) kemungkinan keseragaman standar halal di negara-negara Islam.

Sehubungan dengan izin edar MD yang wajib dimiliki UMKM makanan beku, ternyata sebanyak 76.7\% yang mengetahui izin edar MD (Merk Dalam negri), namun sebanyak 96.7\% tidak memiliki MD. Sebanyak $73.3 \%$ yang mengetahui bahwa izin edar MD adalah wajib bagi pelaku usaha makanan beku, dan sebanyak $76.7 \%$ mengakui mengetahui informasi ini dari pihak selain pemerintah.

Sosialisasi secara intens tentang izin edar MD dan 


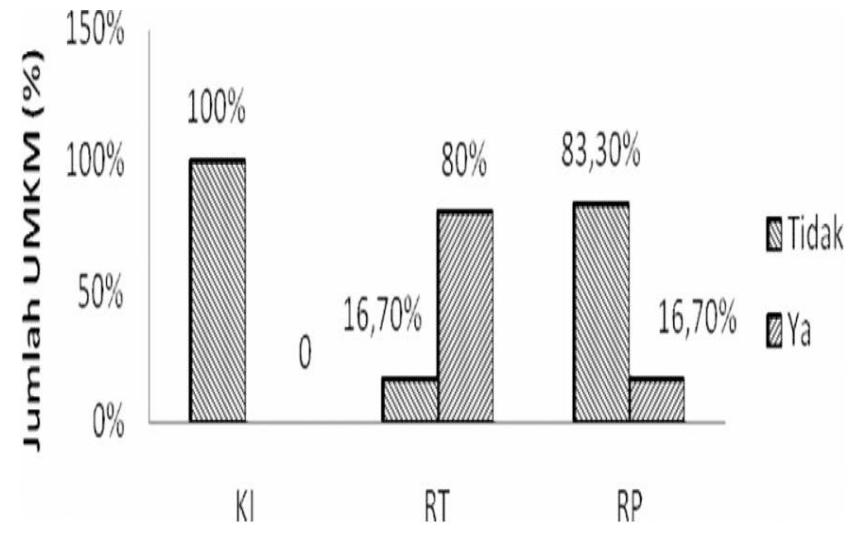

Gambar 5 Tempat produksi UMKM makanan beku di Jabodetabek.

Keterangan:

$\mathrm{KI}=$ Kawasan Industri; $\mathrm{RT}=$ Rumah Tinggal; $\mathrm{RP}=\mathrm{Rumah}$ terpisah

keamanan pangan diharapkan dapat mengubah persepsi tentang rumit dan mahalnya pengurusan izin edar MD sehingga manfaat dari memiliki izin edar MD dipahami dan diimplementasikan oleh UMKM.Borzooei et al. (2013) mengemukakan bahwa perekonomian halal menjadi agenda masyarakat dan katalis perekonomian untuk solusi alternatif terbaik untuk sebagian besar krisis global. Organisasi yang berhasil meningkatkan kualitas produknya dapat meningkatkan produktivitas mereka dalam penetrasi pasar,untuk mencapai profitabilitas yang lebih tinggi (Husainet al.2012).

Pemeriksaaan atau audit yang dilakukan oleh BPOM terhadap pelaku usaha yang mengajukan izin edar MD adalah pelaksanaan cara produksi pangan yang baik atau CPPB-IRT melalui penanganan pangan di seluruh mata rantai produksi mulai dari bahan baku sampai produk akhir yang mencakup: lokasi dan lingkungan produksi, bangunan dan fasilitas, peralatan produksi, suplai air atau sarana penyediaan air, fasilitas dan kegiatan higiene dan sanitasi, kesehatan dan higiene karyawan, pemeliharaan dan program higiene sanitasi karyawan, penyimpanan, pengendalian proses, pelabelan pangan, pengawasan oleh penanggungjawab, penarikan produk, pencatatan dan dokumentasi serta pelatihan karyawan.

Pelaku usaha makanan beku responden penelitian ini seperti tampak pada Gambar 5 sebesar 80\% masih berproduksi di rumah sendiri, berada dalam satu bangunan. Penggunaan dapur yang sama untuk produksi maupun untuk memasak makanan untuk dikonsumsi sendirimenjadi sangat beresiko jika pemilik usahanya bukan Muslim. Penggunaan fasilitas yang sama untuk membuat produk halal dan tidak halal akan menghasilkan produk yang tidak halal dan dipastikan tidak akan mendapatkan sertifikat halal. Tingkat pendidikan tertentu (Abdul et al. 2013) memiliki tanggapan yang berbeda signifikan terhadap proses sertifikasi halal. Pentingnya untuk melihat realitas yang ada pada organisasi di sektor industri halal mengingat bahwa tubuh otoritas akan memengaruhi perilaku pemain (Muhamed et al. 2014). Keterampilan manajemen yang sangat baik diperlukan untuk meningkatkan usaha untuk memantau dan mengendalikan kegiatan mereka dan
Tabel 3.Mesin produksi UMKM makanan beku di Jabodetabek

\begin{tabular}{lc}
\hline Mesin produksi UMKM & Jumlah \\
\cline { 2 - 2 } & $(\%)$ \\
\hline Yang memiliki mesin produksi & 40 \\
Yang harga mesinnya $<50$ juta & 56,7 \\
Yang harga mesinnya $>50$ juta & 30 \\
\hline
\end{tabular}

membuatnya sesuai keinginan pelanggan, pemasok dan persyaratan pemangku kepentingan lainnya (Bohari et al, 2013).Pelaku usaha seperti UMKM pada umumnya merupakan kelompok rentan karena kurangnya sumber daya untuk membangun rantai pasok berdedikasi halal (supply chain).Di Malaysia (Rahmanet al. 2013) saat ini kurang dari $24 \%$ saja perusahaanyang menerapkan kontrol terhadap rantai pasok.Kelompok UMKM harus menggunakan rantai pasok yang baik dalam melakukan pekerjaannya dan jika tidak akan membuat mereka lebih beresiko (Zailani et al. 2010).Berinovasi sangatlah penting dalam menjaga integritas halal sepanjang rantai pasokan, untuk memenuhi permintaan produk halal yang terus meningkat(Tan et al. 2012).Perusahaan logistik harus mempertimbangkan kehadiran pekerja muslim untuk memudahkan penanganan logistik halal (Tarmizi et al. 2014).

Keterbatasan laboratorium pengujian yang ada di Indonesia dalam melakukan uji kehalalan produk dan keterbatasan modal membuat UMKM sulit untuk melakukan pengujian di laboratorium. Sebanyak $16.7 \%$ pelaku usaha berproduksi di rumah sendiri tapi diruangan yang terpisah, namun demikian tetap tidak menjamin keamanannya terutama jika pelaku usahanya bukan Muslim. Dan dengan jelas dari penelitian ini diketahui $100 \%$ UMKM tidak memiliki pabrik (tempat produksi) yang layak.

Pada Tabel 3 tampak pelaku usaha makanan beku pada penelitian ini $40 \%$ memiliki mesin produksi dan sebanyak $56.7 \%$ harga mesinnya kurang dari 50 juta, sisanya sebanyak $30 \%$ harga mesin produksinya bernilai lebih dari 50 juta. Berdasarkan ketentuan dari Undang-Undang Nomor 20 Tahun 2008 tentang kriteria UMKM Bab IV pasal 6,yang memiliki aset kurang dari 50 juta termasuk kelompok usaha mikro dan produk yang dihasilkan belum stabil dalam beberapa hal seperti mutu dan ukuran, karena mesin yang digunakan masih sederhana meskipun sudah berbasis teknologi.Taher (2014) mengemukakan bahwa orientasi pasar, orientasi pengusaha dan budaya organisasi berperan besar dalam meningkatkan kinerja bisnis UMKM.Mohamad (2014) mengemukakan produsen harus berusaha untuk memimpin industri di pasar halal dengan mengembangkan produk yang dilengkapi dengan akreditasi halal sebagai senjata kompetitif.

\section{Strategi untuk mengatasi permasalahan UMKM makanan beku.}

Hasil proses hirarki analisis (AHP) menunjukan penilaian gabungan kriteria dan alternatif memiliki tingkat konsistensi dengan nilai rasio konsistensi $(\mathrm{CR}<0.1)$.

Fokus penelitian ini adalah pelaku UMKM makanan beku mudah mendapat izin edar MD agar 
Tabel 4. Alternatif Strategi

\begin{tabular}{llc}
\hline Alternatif Strategi & Bobot & Prioritas \\
\hline Kemudahan Birokrasi Izin Usaha/Industri & 0,147 & 4 \\
Sentralisasi Tempat Industri & 0,057 & 6 \\
Pembinaan Cara Produksi Pangan yang Benar & 0,343 & 1 \\
Penyediaan Laboratorium Uji & 0,036 & 7 \\
Pembinaan UMKM secara Intens & 0,153 & 3 \\
Biaya Mengurus Izin Edar MD di permurah & 0,094 & 5 \\
Proses Birokrasi MD Dipermudah dan Dipercepat & 0,169 & 2 \\
Consistency Ratio (CR) & 0,06 \\
\hline
\end{tabular}

dapat mengajukan sertifikat halal, tujuan yang menjadi prioritas utamanya adalah peningkatan daya saing produk UMKM makanan beku yang memiliki bobot yang paling tinggi yaitu 0.575 dengan Consistency Ratio $(\mathrm{CR})=0.05$ (konsisten). Peningkatan daya saing sangat dibutuhkan terutama menghadapi serangan produk-produk asing di era perdagangan bebas ini. Sementara aspek yang menjadi prioritas utama adalah aspek proses pendampingan(0.321), yang sangat dibutuhkan oleh UMKM bagaimana berproduksi yang baik dalam upaya menjaga keamanan pangan. Pembinaan yang intens untuk para pelaku usaha ini perlu dilakukan secara lebih baik lagi dan berkesinambungan terlebih menyangkut kebiasan/perilaku manusia khususnya dalam berproduksi pangan halal untuk menjaga keamanan pangan.

Aktor yang paling berpengaruh dari semua aspek adalah BPOM (0.484) karena sumber yang kompeten memberikan pembinaan dan pelatihan berproduksi yang baik guna menghasilkan pangan yang aman adalah BPOM. Jika ada kendala dalam pelaksanaannya karena sumber daya dan waktu yang terbatas, sementara pembinaan harus tersebar merata di seluruh wilayah, BPOM dapat bekerjasama dengan berbagai pihak sebagai perpanjangan tangan BPOM.

Pada aktor PEMDA, faktor yang paling berpengaruh adalah sikap UMKM (0.838) dengan Consistency Ratio 0.00 (konsisten).Sehubungan dengan sejarah para UMKM berwirausaha, setelah berhasil membuat suatu produk mereka langsung menjualnya tanpa mengurus legalitas yang salah satunya adalah izin domisili. Legalitas juga dibutuhkan untuk mengetahui pelaku usaha yang membutuhkan dukungan/ bantuan berupa pelatihan, pembinaan, alokasi dana bantuan dan pemasaran.

Perbaikan sarana dan prasarana (0.572) dengan $\mathrm{CR}=0.07$ (konsisten),merupakan faktor yang paling berpengaruh di UMKM. Hal ini terbukti mekipun UMKM mendapat bantuan berupa pembinaan dan fasilitas lengkap untuk memperoleh izin edar MD banyak diantaranya mengundurkan diri, karena tidak mampu melakukan perbaikan fasilitas produksi.

Pemilihan bahan baku merupakan faktor yang paling penting menurut BPOM (0.233) dengan Consistency Ratio hasil pengolahan data ini 0.03 (konsisten). Pemilihan bahan baku penting karena pelaku usaha mikro memperoleh bahan baku secara curah yang pada umumnya sulit ditelusuri.
Beberapa perizinan dari BPPTPM untuk pelaku UMKM sudah tidak berbiaya, pelayanan berupa fasilitas online pun sudah dilengkapi dengan fasilitas tracking, UMKM sudah bisa melacak sendiri jika ada hambatan dalam mengurus perizinan. Faktor yang paling berpengaruh pada BPPTPM dalam perizinan adalah akte pendirian (0.432) dengan Consistency Ratio hasil pengolahan data ini 0.08 (konsisten).Akte pendirian adalah legalitas pertama yang harus dimiliki sebelum mengurus legalitas atau perizinan yang lainnya.

Alternatif strategi (Tabel 4) yang dapat direkomendasikan dari hasil penelitian ini adalahpembinaan cara produksi pangan yang baik (0.343), proses birokrasi mengurus izin edar MD dipermudah dan dipercepat (0.169)serta pembinaan UMKM secara intens (0.153).

Berdasarkan preferensi pakar tersebut, faktor terpenting untuk mengatasi permasalahan UMKM makanan beku dalam pengajuan sertifikat halal adalah:

a. BPOM

1. Memberikan pendampingan/pembinaan cara produksi yang baik dan sosialisasi izin edar MD serta keamanan pangan.

2. Memberikan kemudahan dan kecepatan birokrasi pengurusan izin edar. Hal ini dapat diwujudkan jika pelaku UMKM memahami keamanan pangan.

b. BPPTPM/Kecamatan:

IUMK di seluruh wilayah segera diimplementasikan dan disosialisasikan.

c. Pemerintah

1. Sentralisasi usaha makanan beku.

2. Bantuan mesin berteknologi lebih modern.

3. Pengadaaan distributor bahan baku baik lokal maupun import bagi UMKM.

4. Lembaga-lembaga pemerintah dapat membantu memfasilitasi UMKM mendapat izin edar MD. 


\section{KESIMPULAN}

UMKM makanan beku di Jabodetabek adalah pelaku usaha mikro, tidak memiliki fasilitas produksi yang layak dan berproduksi menggunakan mesin berteknologi sederhana.Izin edar MD merupakan faktor kendala bagi para UMKM makanan beku mengajukan sertifikat halal. Strategi yang dapat direkomendasikan adalah pembinaan UMKM berproduksi yang baik secara intens dan birokrasi pengurusan MD dipermudah dan dipercepat.

\section{SARAN}

UMKM harus meningkatkan kemampuannya sehingga tidak mengalami kesulitan di dalam memperoleh $\mathrm{MD}$, memberikan jaminan keamanan produk, penggunaan bahan baku yang tertelusur dan dokumentasi yang baik. Penelitian yang perlu dilakukan lebih lanjut adalah mengidentifikasi produk-produk makanan beku yang beredar di pasar yang memiliki logo halal tidak resmi karena jika tidak memiliki izin edar MD maka seharusnya juga tidak memiliki logo halal.

\section{DAFTAR PUSTAKA}

Abdul M, Ismail H, Mustapha M, Kusuma H. 2013. Indonesian Small Medium enterprises (SMEs) and perceptions on Halal food certification.African Journal of Business Management.7(16):1492-1500.

Ahmad H, Fazullah A, Borham AJ. 2011. A Way Forward To Manage Halal Business. Malaysia. International Journal of Arts and Sciences Conference. AUSTRIA. CD ROM Version ISSN 1943-6114.

Alhabshi, SM. 1203. Halal food dilemas: case of muslims in British Columbia, Canada. International Journal of Asian Social Science. 3(4):847-870 847.

Bohari AM, Hin CW, dan Fuad N. 2013. An analysis on the competitiveness of halal food industry in Malaysia: an approach of SWOT and ICT strategy. Journal of Society and Space.9 (1): 1 - 11.

Borzooei M, dan Asgari M. 2013. Establishing a global halal hub: In-depth interviews.International Journal of Academic Research in Business and Social Sciences.3(10):169-181.

Eriyatno SF. 2007. Riset Kebijakan Metoda Penelitian untuk Pascasarjana.Bogor (ID):IPB Pr.

Evans JA. 2008. Frozen Food; Science and Technology. Oxford(UK): Blackwell Publishing.

Halim MA, dan Salleh MM. 2012. The Possibility of Uniformity on Halal Standards in Organization of Islamic Countries (OIC) Country.World Appl Sci J 17 (Towards the Traceability of Halal and Thoyyiban Application): 06-10, Faculty of Syariah and Law, Universiti Sains Islam Malaysia, 71800 Bandar Baru Nilai, Malaysia.

Husain R, Ghani IA, Mohammad, AF; Mehad, S. 2012.Current Practices among Halal Cosmetics Manufacturers in Malaysia.Journal of Statistical Modeling and Analytic 3(1).

[Kemenkop dan UKM RI] Kementrian Usaha Kecil Menengah dan Koperasi. 2013. Rapat Kerja
Kementrian Usaha Kecil Menengah dan Koperasi [Internet].http://www.depkop.go.id.[diakses pada: 17 Juni 2015].

Kordnaeij A, Askaripoor H, Bakhshizadeh A. 2013. Studying affecting factors on customers' attitude toward products with halal brand (case study: Kuala Lumpur Malaysia). International Research Journal of Applied and Basic Sciences. 4 (10): 3138-3145

[LPPOM MUI] Lembaga Pengkajian Pangan Obatobatan dan Kosmetika Majelis Ulama Indonesia. 2013-2014. Indonesia Halal Directory.

Marimin. 2004. Teknik Aplikasi Pengambilan Keputusan Kriteria Majemuk. Jakarta(ID): Grasindo

Mohamad N. 2014. A Framework for the Development of Halal Food Products in Malaysia. Universiti Sains Malaysia, Malaysia. Proceedings of the 2014. International Conference on Industrial Engineering and Operations Management Bali, Indonesia, January 7 - 9, 2014.

Muhamed NA, Ramli NM, Aziz SA, Yaakub NA. 2014. Integrating Islamic Financing and Halal Industry: $A$ Survey on Current Practices of the Selected Malaysian, Asian Social Science; Vol. 10, No. 17; ISSN 1911-2017 E-ISSN 1911-2025 Published by Canadian Center of Science and Education.

Quantaniah NA, Noreina, Syakinah N. 2013. Selecting Halal Food : A Comparative Study Of The Muslim And Non Muslim Malaysian Student Consumer. 2nd International Conference on Technology Management, Business and Entrepreneurship. Malaysia.

Rahman MN, Manzouri, M; Zain, CRCM. Environmental concern in food supply chain.American Journal of Environmental Sciences.9(3): 240-246.

Samori Z, Ishak HA, dan Kassan NH. 2014. Understanding the development of halal food standard: suggestion for future research. International Journal of Social Science and Humanity, 4(6).

Salman F, Siddiqui, K. 2011.An exploratory study for measuring consumers awareness and perceptions towards halal food in Pakistan. Interdisciplinary Journal Of Contemporary Research In Business. 3(2).

Sugiharto et al.2001. Teknik sampling.Gramedia,Jakarta.

Taher IR. 2014. Driver of Organizational innovativeness Among SME's in Malaysia Halal Industry. International Journal of Science Commerce and Humanities. Vol No.2 February 2014. Pahang Malaysia.

Tan MII; Razali, RN; Desa, MI. 2012.Factors Influencing ICT Adoption in Halal Transportations: A Case Study of Malaysian Halal Logistics Service Providers, IJCSI International Journal of Computer Science Issues, Vol. 9, Issue 1, No 2, January 2012.

Tarmizi HA, Kamarulzaman, NH; Atiff, IA; Rahman, A. 2014.Factors behind Third-Party Logistics Providers Readiness towards Halal Logistics, International Journal Supplu Chain Management 3(2).

Zailani SHM, Ahmad ZA, Wahid NA, Othman R,Fernando Y. 2010. Recommendations to strengthen Halal Food Supply Chain for food industry in Malaysia.Journal of 
Agribusiness Marketing.Special Edition.

Zulkarnain M. 2014.Tapping into the

Lucrative Halal Market: Malaysian SMEs Perspective. International Journal of Business and Innovation. Vol. 1, Issue 6, 2014,IRC Publishers 